\title{
Larger body size leads to greater female beluga whale ovarian reproductive activity at the southern periphery of their range
}

\author{
Steven Ferguson ${ }^{1}$, David Yurkowski ${ }^{1}$, Justine Hudson ${ }^{1}$, Tera Edkins ${ }^{1}$, Cornelia Willing ${ }^{1}$, \\ and Cortney Watt ${ }^{1}$ \\ ${ }^{1}$ Fisheries and Oceans Canada
}

July 11, 2021

\begin{abstract}
Identification of phenotypic characteristics in reproductively successful individuals provides important insights into the evolutionary processes that cause range shifts due to environmental change. Female beluga whales (Delphinapterus leucas) from the Baffin Bay region (BB) of the Canadian Arctic in the core area of the species' geographic range have larger body size than their conspecifics at the southern range periphery in Hudson Bay (HB). We investigated the mechanism for this north and south divergence as it relates to ovarian reproductive activity (ORA = total corpora) that combines morphometric data with ovarian corpora counted from female reproductive tracts. Based on the previous finding of reproductive senescence in older HB females, but not for BB whales, we compared ORA patterns of the two populations with age and body length. Female beluga whale ORA increased more quickly with age (63\% partial variation explained) in BB than in HB (41\%). In contrast, body length in HB female beluga whales accounted for considerably more of the total variation (12 vs $1 \%$ ) in ORA compared to $\mathrm{BB}$ whales. We speculate that female HB beluga whale ORA was more strongly linked with body length due to higher population density resulting in food competition that favors the energetic advantages of larger body size during seasonal food limitations. Understanding the evolutionary mechanism of how ORA varies across a species' range will assist conservation efforts in anticipating and mitigating future challenges associated with a warming planet.
\end{abstract}

Larger body size leads to greater female beluga whale ovarian reproductive activity at the southern periphery of their range

Steven H. Ferguson ${ }^{* 1,2}$, David J. Yurkowski ${ }^{1,2}$, Justine M. Hudson ${ }^{1}$, Tera Edkins ${ }^{1}$, Cornelia Willing ${ }^{2}$, and Cortney A. Watt ${ }^{1,2}$

${ }^{1}$ Fisheries and Oceans Canada, Freshwater Institute, Winnipeg, MB, Canada

${ }^{2}$ University of Manitoba, Biological Sciences, Winnipeg, MB, Canada

* corresponding author steve.ferguson@dfo-mpo.gc.ca

Abstract: Identification of phenotypic characteristics in reproductively successful individuals provides important insights into the evolutionary processes that cause range shifts due to environmental change. Female beluga whales (Delphinapterus leucas ) from the Baffin Bay region (BB) of the Canadian Arctic in the core area of the species' geographic range have larger body size than their conspecifics at the southern range periphery in Hudson Bay (HB). We investigated the mechanism for this north and south divergence as it relates to ovarian reproductive activity (ORA $=$ total corpora) that combines morphometric data with ovarian corpora counted from female reproductive tracts. Based on the previous finding of reproductive senescence in older HB females, but not for BB whales, we compared ORA patterns of the two populations with age and body length. Female beluga whale ORA increased more quickly with age (63\% partial variation explained) in $\mathrm{BB}$ than in $\mathrm{HB}$ (41\%). In contrast, body length in HB female beluga whales accounted for considerably 
more of the total variation (12 vs 1\%) in ORA compared to BB whales. We speculate that female HB beluga whale ORA was more strongly linked with body length due to higher population density resulting in food competition that favors the energetic advantages of larger body size during seasonal food limitations. Understanding the evolutionary mechanism of how ORA varies across a species' range will assist conservation efforts in anticipating and mitigating future challenges associated with a warming planet.

Key words: age, body length, Delphinapterus leucas, fitness, geographic range, ovarian corpora

\section{Introduction}

Evolution occurs through natural selection whereby individuals with greater fitness contribute disproportionately more genetic information to future generations. In addition to this individual variation, populations will vary due to adaptations to different environmental selection pressures (Orsini et al. 2008; Coulon et al. 2008; Pauls et al. 2013). Population-level differences in fitness could then vary geographically along an environmental gradient, such as altitude or latitude, based on location within the species' range (Kirkpatrick and Barton 1997; Peterson et al. 2011). For example, sink populations at the periphery of a species' range are constantly in phenotypic flux due to the demographic challenges of living in an environment where speciesspecific traits are less well adapted compared to populations near the core of the species' range (Gaston 2009; Sheth and Angert 2016). It is critical to understand the extent of species-level plasticity that allows individuals to track extreme environmental selection pressures at the edge of their geographic range in our rapidly changing world to inform conservation (Hardie and Hutchings 2010; Valladeres et al. 2014).

Populations at the core of the species' range, where individuals are presumably most suitably adapted to their environment, likely differ from populations at the range periphery where greater phenotypic variation occurs. Reproductive activity is costly and offers a potentially relevant metric to assess the suitability of females to their environment. The ovaries of many mammals provide an index of ovarian reproductive activity (ORA; Marsh et al. 1984; Ellis et al. 2018) and therefore researchers have used lab examinations of female reproductive tracts from sustainably hunted individuals to identify the number of ovarian corpora (Lehmann 1993; Nazarova and Evsikoy 2012; Ringsby et al., 2009). Whales are distinct in that their corpora albicantias (CA) physically remain for the duration of the whale's life, providing a possible way to track an individual's historical record of reproductive events and number of lifetime ovulations (Perrin et al. 1984; Ellis et al., 2018). As a result, we can examine the ovarian reproductive history of individual whales since each CA represents one ovulation, although not necessarily a pregnancy (Berta et al. 2015). During ovulation, an oocyte is released from the Graafian follicle with the rupture site forming the corpus luteum (CL), a temporal bright yellow, hormonal gland helping to promote and to maintain implantation of the embryo. Subsequently, this body regresses to a CA which is generally considered to persist within the ovarian tissue throughout the life of a female whale even after diminishing in size and color (Mackintosh, 1942; Laws, 1961; Fujino 1963).

Relating phenotypic characteristics to lifetime reproductive activity can provide important insight into evolutionary processes and allow comparisons between populations that may indicate adaptation (Peterson et al. 2019). We thus need to assess the contribution of variation in phenotypic traits, such as body size, to reproductive variation (Gaillard et al. 2000), in order to understand key variables for survival and reproductive success.

Large mammalian females are generally considered to be capital breeders (Stearns 1992) and, therefore, should illustrate a strong relationship between individual body size and reproductive activity. Despite relationships between reproductive metrics and body size being investigated across several mammalian species (pinnipeds (Le Boeuf \& Reiter 1988), ungulates (Clutton-Brock et al. 1988), and rodents (Ribble 1992), this relationship has not been demonstrated in whales, likely due to the logistical difficulties of measuring adult body size and reproduction over an individual's lifetime. Odontocete (toothed) whales generally live in cooperative societies where selection on female dominance likely operates through variation in body size (Ward et al. 2009; Croft et al. 2017). Despite this, no studies have investigated the factors that influence female ORA, age, and body size in odontocete whales. 
There are 21 beluga whale (Delphinapterus leucas ) populations across the Arctic providing a latitudinal continuum of populations within their range (Hobbs et al. 2020). A collection of tissue samples provided by Inuit hunters during subsistence hunts from across the eastern Canadian Arctic have been archived by Fisheries and Oceans Canada and include female beluga whale reproductive tracts with ovaries. To date, this collection has revealed spatial differences in morphology, phylogenetic history, demography, and reproduction between individuals wintering in the Hudson Bay (HB) region, compared to those wintering in Baffin Bay (BB) (Postma 2017; Ferguson et al. 2020) (Fig. 1). For this study, we chose to compare the HB whales, representing adaptations to life at the southern periphery of the beluga whale geographic range $\left(59^{\circ}\right.$ latitude), to $\mathrm{BB}$ whales $\left(73^{\circ}\right.$ latitude) representing adaptations to life within the core of the species' range. Knowing that HB whales are smaller than BB whales (Stewart 1994), our objective was to determine whether female body size differences relating to ORA occurred between peripheral HB and core BB regions while controlling for age. Specifically, we determined how variation in ORA, measured as total ovarian corpora counts, relates to body size of female beluga whales from both populations.

Methods

The dataset included 172 female reproductive tracts with at least one corpus: 41 from BB and 131 from HB. To create a complete dataset required for robust statistical testing (Moritz \& Bartz-Beielstein 2017), missing length and age data were replaced with the median value of all whales in each population. The five BB whales with missing age were assigned 20 years-of-age and the 6 HB whales, 26 years-of-age. Similarly, the $6 \mathrm{BB}$ whales with missing length were assigned $354 \mathrm{~cm}$ and the $17 \mathrm{HB}$ whales with missing length, $327 \mathrm{~cm}$. We conducted post-mortem gross examinations of female reproductive tracts, collected from 17 northern communities within the Eastern Canadian Arctic from 1989 to 2014 (Fig. 1). Ageing was based on examination of dentine and cementum growth layer groups in teeth (Waugh et al. 2018). Whale standard length was measured in the field according to a standard protocol, measured from the middle of the fluke to the tip of the rostrum (American Society of Mammalogists, 1961). We combined reproductive morphology data for two northern populations (Cumberland Sound and high Arctic) into a BB region based on a similar growth-age-reproduction relationship (Ferguson et al. 2020). For consistency in terminology, we refer to $\mathrm{BB}$ and $\mathrm{HB}$ as populations while recognizing that each region likely comprises a number of sub-populations (Skovrind et al. 2021).

Sample processing is described in more detail in Ferguson et al. (2020); briefly, ovaries were excised, weighed, measured, and preserved in 10\% neutral-buffered formalin. For each ovary, we recorded the number of CLs and CAs (Best, 1968). In cetaceans CLs and CAs form distinct and persistent features, accumulating within the ovary (Perrin et al. 1976) as a record of a female's potential reproductive history (Slijper 1962; Collet and Harrison et al., 1972; but see Dabin et al. 2008). Corpora assessments were performed by one reader to minimize bias in the subjective determination of accessory corpora (Harrison, 1977). As a measure of ORA, we counted all existing CLs and CAs within the beluga whales' ovaries. For whales with only one ovary sampled ( 23 of 97 whales from BB and 113 of 210 whales from HB), we doubled the corpora count since beluga whales do not appear to exhibit a side-dominance in ovarian function (Robeck et al. 2010; Sheldon et al. 2019).

\section{Statistical analysis}

A Generalized Linear Mixed Model fit by maximum likelihood (Laplace approximation) with a Poisson distribution (Coxe et al. 2009) was used to assess differences in ORA between the two regions. Poisson regression models are best used for modeling events where the outcomes are counts or, more specifically, discrete data with non-negative integer values. Generalized Linear Models are models in which response variables follow a distribution other than the normal distribution. Knowing that the relationships between ORA and age or body length are non-linear (Lamaître et al. 2015), we transformed the non-linear relationship to linear form using a link function creating a log-linear model, whereby the coefficients are calculated using maximum quasi-likelihood. Region (categorical), age (continuous), and length (continuous) were included as fixed effects and year as a random effect. Model selection was guided by Variance Inflation Factors (VIF) and Akaike's information criterion for small sample size (AICc) using information theory (Burnham and 
Anderson 2002). We calculated log-likelihood (LL), AICc values, [?]AICc, and AICc weights (wi - relative likelihood of the model) using MuMIn (version 1.43.17; Zuur et al., 2009; Mazerolle, 2019). First (Step 1), we tested the full model to determine whether the effect of length and age on ORA differed by region. Then (Step 2), we addressed region-specific relationships by removing region as a fixed effect and running separate models for each region. Our study employed a limited set of a priori models (i.e., $\mathrm{n}=6$ ), and therefore we report all top models (Delta $([?] \mathrm{AICc})<3.0)$ while accepting that models with AIC scores near the top-ranked model might not be as competitive based on consideration of model deviance (Burnham and Anderson 2002; Arnold 2010). All statistical analyses and graphics were performed using R statistical software (v. 3.6.3).

The effect of body size on ORA was assessed for each region separately while controlling for whale age. We used partial correlations which measured the "unique" contribution of an independent variable (age and body length) to $\mathrm{r}^{2}$ of the model. Here, we followed the "hierarchical analysis procedure" where the order of variable entry affected analysis and interpretation of partials (Cohen and Cohen 1975). As a result, length was the first predictor variable entered into the model, due to length being the primary variable of interest to answer our hypotheses, followed by age. The partial correlation analysis assumes linearity in the relationships among ORA, age, and length, which we tested with residual plots (Zuur et al. 2010). To display possible nonlinearities, we used LOESS (locally estimated scatterplot smoothing) in the figures as a non-parametric regression method that combines multiple regression models in a k-nearest-neighbor-based meta-model (Owolabi et al. 2016).

Results

Whales from HB displayed greater ORA (range 1-35, median 8, mean 10.3) than BB (range 1-23, median 6 , mean 7.8) although the difference was marginal $\left(\mathrm{F}_{1,170}=3.78, \mathrm{p}=0.05\right)$. For age distribution, $\mathrm{BB}$ whales (range 8-46, median 21, mean 23.5) were younger than HB whales (range 10-68, median 27, mean 29.5; $\mathrm{F}_{1,170}=7.77, \mathrm{p}<0.01$ ). For length, BB whales (range 204-447, median 362, mean 359.6) were larger than HB (range 189-455, median 333, mean 333.5; $\mathrm{F}_{1,170}=12.2, \mathrm{p}<0.001$ ) (Fig. 2).

The effect of region (BB and HB) (Step 1) on ORA was assessed in a complete model (ORA length + age + region $+(1 \mid$ year $))$. Model selection supported two different models $(\Delta \mathrm{AIC}<1)$ (Table 1$)$. One of these models found a difference in ORA between regions $($ Delta $=0.160)$ and in conjunction with prior knowledge of regional differences, we contrasted BB and HB using separate GLM models to discover any region-specific age and length relationships (Step 2). For BB beluga whales, length was not a predictor of ORA whereas both age and length were predictors for HB beluga whales (Table 1).

Finally, we used partial correlations to account for explained variation only attributable to length. For BB beluga whales, length explained $0.4 \%$ of variation in ORA while controlling for age, whereas age explained $63.6 \%$ of variation in ORA. For HB beluga whales, length explained $5.7 \%$ of the variation in ORA while controlling for age, whereas age explained $41.4 \%$ of variation in ORA. For BB beluga whales, the rate of increase in ORA with age was 1.5 times greater than HB $(0.50$ versus 0.33 ORA per year, $\mathrm{t}=-2.17, \mathrm{p}=$ $0.031)$, while the rate of increase in ORA with length did not differ between populations $(\mathrm{t}=0.53, \mathrm{p}=0.96$; Fig. 3). However, HB whales had higher ORA for similar body lengths $(\mathrm{t}=2.95, \mathrm{p}=0.0037)$. Length explained $1 \%$ of the total variation in ORA for BB beluga whales $(0.4 \% /(0.4 \%+63.3 \%) * 100 \%)$ compared to $12 \%$ of ORA explained by length for HB $(5.7 \% / 5.7 \%+41.4 \%) * 100 \%)$.

\section{Discussion}

Population-level differences in ovarian reproductive activity (ORA) could be an adaptation to environmental selection pressures that vary along latitudinal gradients (Orsini et al. 2008; Coulon et al. 2008; Pauls et al. 2013). Although ORA did not differ among beluga whales along a latitudinal continuum, for the southern population of female beluga whales at the periphery of the species' geographic range, ORA was more strongly influenced by body size than ORA of populations within the core northern range. Additionaly, body size was a greater predictor of ORA for female HB beluga whales living at the southern edge of their distribution compared to $\mathrm{BB}$ whales living in core northern range. If this finding holds for other species facing similar 
selective pressures from climate warming, then our results provide critical information on a mechanism of redistribution and underscores limits to opportunities for adaptation in changing environments.

In females, fecundity selection, which selects for traits that increase the number of offspring successfully raised, is a major driver of body size, whereas in males, sexual selection is a major evolutionary force selecting for larger body size (Ralls 1977). Fecundity selection in females is an adaptation that needs to be balanced with survival (Pincheira-Donoso and Hunt, 2017). For example, selection for large female body size is counterbalanced by opposing selective forces that may include (1) increased risk from predation, parasitism, or starvation because of their large size (e.g., reduced agility, increased detectability, higher energy requirements, heat stress) and (2) a longer developmental time to attain larger size which may result in a later age of sexual maturity and decreased lifetime reproductive success (Blanckenhorn 2000).

Linear increases in age with reproductive success are expected as the number of offspring born to a female accumulates over time; however, non-linear effects such as a decline in reproduction with advancing age are more challenging to explain or confirm. For a limited number of wild cetaceans, lifetime reproductive success reaches a plateau at oldest ages when they stop reproducing (Perrin et al., 1976; Mizroch 1981; March and Kasuya 1984). The number of beluga whale CAs has been found to increase up to approximately 40 years of age (Brodie 1972, Heide-Jørgensen and Teilmann 1994, Suydam 2009, Ferguson et al. 2020). After 40 years of age, a decline in ORA was found in the HB population at the southern limit of the species' distribution (Ferguson et al. 2020), but there was no decline in ORA with age for the core BB population (although there were fewer older females in the BB hunter-collected samples compared to HB (see Ferguson et al. 2020)). This lack of a decline in reproduction with advancing age in BB beluga whales may characterize a growing population of younger whales recovering from past overexploitation (Wade et al., 2012) or an evolved life-history adaptation of a population selected for life in core range (i.e., source vs sink; Kozłowski 1993).

It is unclear why larger body size among female beluga whales is more strongly correlated with ORA in a population of smaller-bodied whales living near the southern periphery of their geographic range. It is possible that although larger body size is favored by females in the southern population, due to the high population density relative to food availability, they may struggle to grow to a size similar to that found in northern areas (Luque and Ferguson 2010). For the smaller-bodied whales of southern populations, individual selection may be strong for large females because of the advantages accrued with greater fat storage capability and the associated survival advantages during seasonal food limitation (Lindsteadt and Boyce 1985). Similarly, we would predict that southern populations would select for longer nursing duration due to the advantages provided by greater offspring growth and survival (Beauplet and Guinet 2007; Matthews and Ferguson 2015). In contrast, the northern population lives at lower population density and likely without food limitation and thus can grow to a larger body size. Food limitation in southern areas, would contrast with density-independent limitation through ice entrapments in northern areas, where differences in body size may not provide survival advantages (Heide-Jørgensen et al. 2002, Luque and Ferguson 2010).

Another consideration is the contrasting demographic history between the two regions and how long-term changes in population dynamics can drive differences in ORA. The pristine, pre-commercial whaling abundance of the BB population was previously estimated to be double that of the most recent population abundance estimate from 1996 of 21,213 beluga whales (Innes et al. 2002; Innes and Stewart 2002). Although, the population growth trend has been interpreted as increasing, the Baffin Bay population as a whole is still considered depleted due to past commercial whaling (Hobbs et al., 2020). Similarly, the Cumberland Sound population, also located in the BB region, is considered depleted due to past overharvesting from commercial whaling practices (Sergeant and Brodie 1975) with a current abundance estimated at 1,381 or $15 \%$ of the original estimated population size (Watt et al. 2020). In contrast, the HB population is considered to be possibly the largest in the world, at a minimum size of 54,473 beluga whales (Matthews et al. 2017). Although considerable commercial harvesting of HB beluga whales occurred over the past century (Mitchell and Reeves 1981), the population is likely at or near carrying capacity (Hammill et al., 2017; Hobbs et al., 2020). Demographic rates differed between the beluga whale populations studied here and research has shown that long-term population dynamics can not only fluctuate over time, but drive large differences in reproduction 
(Ozgul et al. 2006; Boyce et al., 2006; this study).

Despite the large number of samples provided by Inuit hunters from across Nunavut, the number of intact and complete female reproductive tracts with ovaries and associated morphometric information was moderate. As a result, we were unable to consider other covariates that may explain ORA variation, such as temporal trends that could be associated with environmental shifts. In addition, since hunters are somewhat selective in the size of harvested whales, there is the possibility of bias in the whales hunted (e.g., health), although we would expect this possible bias to be similar between our two study regions. Another data uncertainty is whether CAs in older females become progressively smaller and more difficult to detect (Suydam 2009). Interpreting ORA of beluga whales is made difficult because of the occurrence of accessory corpora (Burns and Seaman 1986) and younger females may produce more accessory corpora than older ones (Brodie 1971; Harrison et al. 1972; Perrin et al. 1984). Greater ORA may also indicate more successful reproduction, resulting in the birth of calves that may or may not survive to reproduce themselves. An unsuccessful pregnancy or calf mortality could result in a shorter reproductive interval and earlier ovulation resulting in a possible bias; similarly, successful pregnancy can result in fewer CAs since ovulation does not occur during the gestation period (Cha et al., 2012). The persistence of CAs provides a measure of the number of successful ovulation events, but it does not provide additional information on reproductive success following birth. We expect these possible biases to be consistent across both regions and are unlikely to affect the comparison of patterns between populations located along a latitudinal continuum; however, it is a limitation of the study. Our statistical assessment of partial correlation assumed linear relationships among ORA, age, and length in order to partition the variance to understand the relationship between ORA and length while controlling for age. However, nonlinearity was evident, particularly for age and ORA, indicating that nonparametric approaches may also be applicable to understand questions unrelated to variance, and should be explored with a larger sample size.

Understanding the evolutionary mechanisms for animal adaptations to shifting environments via changes in life-history parameters will assist conservation efforts in anticipating and possibly ameliorating future demographic challenges associated with a warming world (Sæther et al. 1996; Stockwell et al. 2003; Hazen et al., 2013). For example, increasing anthropogenic stress from contaminants, noise, and conflicts with fisheries may exacerbate reproductive costs to beluga whales (Mosnier et al., 2015; Norman et al. 2015). Furthermore, contemporary evolution might reduce reproductive success through interactions between population size and strength of selection making most conservation efforts risky unless they can measure and account for changes in fitness (Fernández and Caballero 2001). More insight is required to understand the complex relationships between changing evolutionary pressures and population dynamics, such as fecundity, individual body growth patterns, sociality, and genetic traits to strengthen conservation efforts, thus ensuring long-term species persistence.

Acknowledgements: We thank the Inuit hunters and the Hunters and Trappers Associations of Nunavut, Canada, for collecting beluga whale reproductive tracts through community-based monitoring. Funding was provided by Nunavut Wildlife Management Board, Fisheries and Oceans Canada, and Natural Sciences and Engineering Research Council of Canada. The Associate Editor, an anonymous reviewer and J.M. Gaillard provided generous comments that helped improve the manuscript.

\section{Literature Cited}

American Society of Mammalogists. 1961. Standardized methods for measuring and recording data on the smaller cetaceans. Journal of Mammalogy 42(4):471 -476.

Arnold, T.W., 2010. Uninformative parameters and model selection using Akaike's Information Criterion. The Journal of Wildlife Management, 74(6), pp.1175-1178.

Beauplet, G. and Guinet, C., 2007. Phenotypic determinants of individual fitness in female fur seals: larger is better. Proceedings of the Royal Society B: Biological Sciences, 274(1620), pp.1877-1883. https://doi.org/10.1098/rspb.2007.0454 
Berta, A., Sumich, J.L. and Kovacs, K.M., 2015. Reproductive structures, strategies, and patterns. In: Marine Mammals: Evolutionary Biology, Pages 465-532, Academic Press. https://doi.org/10.1016/B978-012-397002-2.00013-2

Best, P.B. 1968. The sperm whale (Physeter catodon) off the west coast of Southern Africa. 2. Reproduction in the female. Investigational Report of the Division of Sea Fisheries South Africa 66:1-32.

Blanckenhorn, W.U., 2000. The evolution of body size: what keeps organisms small?. The quarterly review of biology, 75(4), pp.385-407.

Boyce M.S., C.V. Haridas, C.T. Lee, NCEAS Stochastic Demography Working Group. Demography in an increasingly variable world. Trends Ecol. Evol., 21 (2006), pp. 141-148, 10.1016/j.tree.2005.11.018

Brodie, P.F. 1971. A reconsideration of aspects of growth, reproduction and behavior of the white whale (Delphinapterus leucas) with reference to the Cumberland Sound, Baffin Island population. J. Fish. Res. Board Can. 28:1309-1318.

Brodie, P.F., 1972. Significance of accessory corpora lutea in odontocetes with reference to Delphinapterus leucas. Journal of mammalogy, 53(3), pp.614-616.

Burnham K, Anderson D. 2002. Model selection and multi-model inference: a practical information-theoretic approach. New York: Springer-Verlag.

Burns, J.J. and G.A. Seaman. 1986. Investigations of belukha whales in coastal waters of western and northern Alaska. II. Biology and ecology. U.S. Department of Commerce, NOAA, OCSEAP Final Report 56:221-357.

Cha, J., Sun, X. and Dey, S.K., 2012. Mechanisms of implantation: strategies for successful pregnancy. Nature medicine, 18(12), pp.1754-1767.

Clutton-Brock, T.H., Albon, S.D. and Guinness, F.E., 1988. Reproductive success in male and female red deer. Reproductive success, pp.325-343.

Cohen, J. , \& Cohen, P. 1975. Applied multiple regression/correlation analysis for the behavioral sciences. Hillsdale NJ: Lawrence Erlbaum.

Collet A, Harrison RJ (1981) Ovarian characteristics, corpora lutea and corpora albicanta in Delphinus delphis stranded on the Atlantic coast of France. Aquat. Mamm. 8:69-76

Coulon, A., Fitzpatrick, J.W., Bowman, R., Stith, B.M., Makarewich, C.A., Stenzler, L.M. and Lovette, I.J., 2008. Congruent population structure inferred from dispersal behaviour and intensive genetic surveys of the threatened Florida scrub-jay (Aphelocoma coerulescens). Molecular Ecology, 17(7), pp.1685-1701.

Coxe, S., West, S.G. and Aiken, L.S., 2009. The analysis of count data: A gentle introduction to Poisson regression and its alternatives. Journal of personality assessment, 91(2), pp.121-136.

Croft, D.P., Johnstone, R.A., Ellis, S., Nattrass, S., Franks, D.W., Brent, L.J., Mazzi, S., Balcomb, K.C., Ford, J.K. and Cant, M.A., 2017. Reproductive conflict and the evolution of menopause in killer whales. Current Biology, 27(2), pp.298-304.

Dabin, W., Cossais, F., Pierce, G.J. and Ridoux, V., 2008. Do ovarian scars persist with age in all Cetaceans: new insight from the short-beaked common dolphin (Delphinus delphis Linnaeus, 1758). Marine Biology, 156(2), pp.127-139.

Ellis, S., Franks, D.W., Nattrass, S., Currie, T.E., Cant, M.A., Giles, D., Balcomb, K.C. and Croft, D.P., 2018. Analyses of ovarian activity reveal repeated evolution of post-reproductive lifespans in toothed whales. Scientific reports, 8(1), pp.1-10. 
Ferguson S.H., Willing C., T.C. Kelley, D.A. Boguski, D.J. Yurkowski, and C.A. Watt. 2020. Reproductive parameters for female beluga (Delphinapterus leucas) whales of the Eastern Canadian Arctic. Arctic accepted 9July2020.

Fernandez, J. and Caballero, A., 2001. A comparison of management strategies for conservation with regard to population fitness. Conservation Genetics, 2(2), pp.121-131.

Fujino, K.A.Z.U.O., 1963. Intra-uterine selection due to maternal-fetal incompatibility of blood types in the whales. Sci. Rep. Whales Res. Inst. no. 17, pp.53-65.

Gaillard, J.M., Festa-Bianchet, M., Yoccoz, N.G., Loison, A. and Toigo, C., 2000. Temporal variation in fitness components and population dynamics of large herbivores. Annual Review of ecology and Systematics, 31(1), pp.367-393.

Gaston, K.J. 2009. Geographic range limits: achieving synthesis. Proceedings of the Royal Society B: Biological Sciences 276 (1661), 1395-1406.

Hammill, M.O., Mosnier, A., Gosselin, J.-F., Matthews, C.J.D., Marcoux, M., and Ferguson, S.H. 2017. Management Approaches, Abundance Indices and Total Allowable Harvest levels of Belugas in Hudson Bay. DFO Can. Sci. Advis. Sec. Res. Doc. 2017/062. iv + 43 p.

Hardie, D.C. and Hutchings, J.A., 2010. Evolutionary ecology at the extremes of species' ranges. Environmental Reviews ,18 (NA), pp.1-20.

Harrison RJ, Brownell RL Jr, Boice RC. 1972. Reproduction and gonadal appearances in some odontocetes. In: Harrison RJ (ed) Functional anatomy of marine mammals, vol 1. Academic Press, New York, pp 361-429

Harrison, R.J. 1977. Ovarian appearances and histology in Tursiops truncates. Pp. 195-204. In: S. H. Ridgway and K. Benirschke (eds), Breeding Dolphins: Present Status, Suggestions for the Future. National Technical Information Service, PB-273673, U.S.. Department of Commerce, Springfield, Virginia.

Hazen, E.L., Jorgensen, S., Rykaczewski, R.R., Bograd, S.J., Foley, D.G., Jonsen, I.D., Shaffer, S.A., Dunne, J.P., Costa, D.P., Crowder, L.B. and Block, B.A., 2013. Predicted habitat shifts of Pacific top predators in a changing climate. Nature Climate Change, 3(3), pp.234-238.

Heide-Jorgensen, M.P., Teilmann, J. and Heide-Jorgensen, M.P., 1994. Growth, reproduction. age structure and feeding habits of white whales (Delphinapterus leucas) in West. Studies of White Whales (Delphinapterus leucas) and Narwhals (Monodon monoceros) in Greenland and Adjacent Waters, p.195. Meddelelser om Gronland, Bioscience 39: 195-212.

Heide-Jorgensen, M.P., Richard, P., Ramsay, M. and Akeeagok, S., 2002. Three recent ice entrapments of Arctic cetaceans in West Greenland and the eastern Canadian High Arctic. NAMMCO Scientific Publications, 4, pp.143-148.

Hobbs, R. C., R. R. Reeves, J. S. Prewitt, G. Desportes, K. Breton-Honeyman, T. Christensen, J. J. Citta, S. H. Ferguson, K. J. Frost, Eva Garde, M. Gavrilo, M. Ghazal, D. M. Glazov, J.-F. Gosselin, M. Hammill, R. G. Hansen, L. Harwood, M. P. Heide-Jorgensen, G. Inglangasuk, K. M. Kovacs, V. V. Krasnova, D. M. Kuznetsova, D. S. Lee, V. Lesage, D. I. Litovka, E. D. Lorenzen, L. F. Lowry, C. Lydersen, C. J. D. Matthews, I. G. Meschersky, A. Mosnier, G. O'Corry-Crowe, L. Postma, L. T. Quakenbush, O. V. Shpak, M. Skovrind, R. S. Suydam, and C. A. Watt. 2020. Global review of the conservation status of Monodontid stocks. Marine Fisheries Review 81(3-4): 1-53. https://doi.org/10.7755/MFR.81.3-4.1

Innes, S. and Stewart, R.E., 2002. Population size and yield of Baffin Bay beluga (Delphinapterus leucas) stocks. NAMMCO Scientific Publications, 4, pp.225-238.

Innes, S., Heide-Jorgensen, M.P., Laake, J.L., Laidre, K.L., Cleator, H.J., Richard, P. and Stewart, R.E., 2002. Surveys of belugas and narwhals in the Canadian high Arctic in 1996. NAMMCO Scientific Publications, 4, pp.169-190. 
Kirkpatrick, M. and Barton, N.H., 1997. Evolution of a species' range.The American Naturalist, 150 (1), pp.1-23.

Kozłowski, J., 1993. Measuring fitness in life history studies. Trends in Ecology \& Evolution, 8(3), pp.84-85.

Lemaître, J.F., Berger, V., Bonenfant, C., Douhard, M., Gamelon, M., Plard, F. and Gaillard, J.M., 2015. Early-late life trade-offs and the evolution of ageing in the wild. Proceedings of the Royal Society B: Biological Sciences, 282(1806), p.20150209.

Laws, R.M. 1961. Reproduction, growth and age of southern fin whales. Discovery Report, 31: 327-486.

Le Boeuf, B.J. and Reiter, J., 1988. Lifetime reproductive success in northern elephant seals. Reproductive success. University of Chicago Press, Chicago, pp.344-362.

Lehmann, T., 1993. Ectoparasites: direct impact on host fitness. Parasitology today, 9(1), pp.8-13.

Lindstedt, S.L. and Boyce, M.S., 1985. Seasonality, fasting endurance, and body size in mammals. The American Naturalist, 125(6), pp.873-878.

Luque, S.P. and Ferguson, S.H., 2010. Age structure, growth, mortality, and density of belugas (Delphinapterus leucas) in the Canadian Arctic: responses to environment? Polar Biology, 33(2), pp.163-178.

Mackintosh, N.A. 1942. The southern stocks of whalebone whales. Discovery Report 22: 197-300.

Marsh, H. and T. Kasuya. 1984. Changes in the ovaries of the short-finned pilot whale, Globicephala macrorhynchus, with age and reproductive activity. In: W.R. Perrin, R.L. Brownell, and D.P. DeMaster (eds.). Reproduction in whales, dolphins and porpoises. Rep. int. Whal. Commn. (Special Issue 6), Cambridge, UK. Pp.311-335.

Marsh, H., Heinsohn, G.E. and Channells, P.W., 1984. Changes in the ovaries and uterus of the dugong, Dugong dugon (Sirenia: Dugongidae), with age and reproductive activity. Australian Journal of Zoology, 32(6), pp.743-766.

Matthews, C.J. and Ferguson, S.H., 2015. Weaning age variation in beluga whales (Delphinapterus leucas). Journal of Mammalogy, 96(2), pp.425-437.

Matthews, C.J., Watt, C.A., Asselin, N.C., Dunn, J.B., Young, B.G., Montsion, L.M. and Marcoux, M., 2017. Estimated abundance of the Western Hudson Bay beluga stock from the 2015 visual and photographic aerial survey. Canadian Science Advisory Secretariat (CSAS).

Mitchell E., and Reeves R. R. 1981. Catch history and cumulative catch estimates of initial population size of cetaceans in the eastern Canadian Arctic. Reports of the International Whaling Commission, 31, 645-682.

Mizroch, S.A. 1981. Analyses of some biological parameters of the Antarctic fin whale (Balaenoptera physalus). Rep. int. Whal. Commn. 31:425-434.

Moritz S., Bartz-Beielstein T. 2017. imputeTS: Time Series Missing Value Imputation in R. The R Journal, 9(1): 207-218. doi: 10.32614/RJ-2017-009 (URL: https://doi.org/10.32614/RJ-2017-009).

Mosnier, A., Doniol-Valcroze, T., Gosselin, J.F., Lesage, V., Measures, L.N. and Hammill, M.O., 2015. Insights into processes of population decline using an integrated population model: The case of the St. Lawrence Estuary beluga (Delphinapterus leucas). Ecological Modelling, 314, pp.15-31.

Nazarova, G.G. and Evsikov, V.I., 2012. The evolutionary ecology of animal fertility: the fitness of progeny is determined by their prenatal development (according to the example of the european water vole, Arvicola terrestris L.). Russian Journal of Genetics: Applied Research, 2(1), pp.23-28.

Norman, S.A., Hobbs, R.C., Goertz, C.E., Burek-Huntington, K.A., Shelden, K.E., Smith, W.A. and Beckett, L.A., 2015. Potential natural and anthropogenic impediments to the conservation and recovery of Cook Inlet beluga whales, Delphinapterus leucas. Mar. Fish. Rev, 77(2), pp.89-105. 
Owolabi, B.B., Yusuf, O.B., Afonne, C., Afolabi, N.B. and Ajayi, I.O., 2016. Parametric and non parametric estimates of malaria attributable fractions among children in South West Nigeria. American Journal of Mathematics and Statistics, 6(2), pp.79-85.

Orsini, L., Corander, J., Alasentie, A. and Hanski, I., 2008. Genetic spatial structure in a butterfly metapopulation correlates better with past than present demographic structure. Molecular ecology, 17(11), pp.2629-2642.

Ozgul A., K.B. Armitage, D.T. Blumstein, M.K. Oli. Spatiotemporal variation in survival rates: implications for population dynamics of yellow-bellied marmots. Ecology, 87 (2006), pp. 1027-1037

Pauls, S.U., Nowak, C., Bálint, M. and Pfenninger, M., 2013. The impact of global climate change on genetic diversity within populations and species. Molecular ecology, 22(4), pp.925-946.

Perrin, W.F., Coe, J.M., and Zweifel, J.R. 1976. Growth and reproduction of the spotted porpoise, Stenella truncatus, in the offshore eastern tropical Pacific. Fishery Bulletin 74:229-269.

Perrin, W. F., Brownell, R. L. Jr. \& DeMaster, D. P. 1984. Reports of the International Whaling Commsion: Reproduction in whales, dolphins and porpoises.

Peterson, A.T., Soberón, J., Pearson, R.G., Anderson, R.P., Martínez-Meyer, E., Nakamura, M. and Araújo, M.B., 2011. Ecological niches and geographic distributions (MPB-49) (Vol. 49). Princeton University Press.

Peterson, M.L., Doak, D.F. and Morris, W.F., 2019. Incorporating local adaptation into forecasts of species' distribution and abundance under climate change. Global Change Biology, 25(3), pp.775-793.

Pincheira-Donoso, D. and Hunt, J., 2017. Fecundity selection theory: concepts and evidence. Biological Reviews, 92(1), pp.341-356.

Postma, L. 2017. Genetic diversity, population structure and phylogeography among belugas (Delphinapterus leucas) in Canadian waters: broad to fine-scale approaches to inform conservation and management strategies. PhD thesis. University of Manitoba, Department of Biological Sciences. 296 pp.

Ralls, K., 1977. Sexual dimorphism in mammals: avian models and unanswered questions. The American Naturalist, 111(981), pp.917-938.

Ribble, D.O., 1992. Lifetime reproductive success and its correlates in the monogamous rodent, Peromyscus californicus. Journal of Animal Ecology, pp.457-468.

Ringsby, T.H., Berge, T., Saether, B.E. and Jensen, H., 2009. Reproductive success and individual variation in feeding frequency of House Sparrows (Passer domesticus). Journal of Ornithology, 150(2), pp.469-481.

Robeck, T.R., Steinman, K.J., Montano, G.A., Katsumata, E., Osborn, S., Dalton, L., Dunn, J.L., Schmitt, T., Reidarson, T. and O'Brien, J.K., 2010. Deep intra-uterine artificial inseminations using cryopreserved spermatozoa in beluga (Delphinapterus leucas). Theriogenology, 74(6), pp.989-1001.

Saether, B.E., Ringsby, T.H. and Roskaft, E., 1996. Life history variation, population processes and priorities in species conservation: towards a reunion of research paradigms. Oikos, pp.217-226.

Sergeant, D.E. 1973. Biology of white whales (Delphinapterus leucas) in western Hudson Bay. J. Fish. Res. Board. Can. 30:1065-1090.

Sergeant, D.E. and Brodie, P.F., 1975. Identity, abundance, and present status of populations of white whales, Delphinapterus leucas, in North America. Journal of the Fisheries Board of Canada, 32(7), pp.10471054 .

Shelden, K.E., Burns, J.J., McGuire, T.L., Burek-Huntington, K.A., Vos, D.J., Goertz, C.E., O'CorryCrowe, G. and Mahoney, B.A., 2019. Reproductive status of female beluga whales from the endangered Cook Inlet population. Marine Mammal Science 36:690-699. https://doi.org/10.1111/mms.12648 
Sheth, S.N. and Angert, A.L., 2016. Artificial selection reveals high genetic variation in phenology at the trailing edge of a species range. The American Naturalist, 187(2), pp.182-193.

Skovrind, M., Louis, M., Westbury, M., Garilao, C., Kaschner, K., Samaniego, J., Gopalakrishnan, S., Knudsen, S., Haile, J., Dalen, L., Chernetsky, A., Glazov, D., Krasnova, V.V., Meschersky, I., Rozhnov, V., Litovka, D., Shpak, O., Lydersen, C., Kovacs, K., Heide-Jorgensen, M. P., Postma, L., Ferguson, S., Lorenzen, E. 2021. Circumpolar phylogeography and demographic history of beluga whales reflect past climatic fluctuations. Molecular Ecology accepted 15Feb2021.

Slijper, E.J. 1962. Whales. Hutchinson \& Co., Ltd., London. 475 pp.

Stearns, S.C., 1992. The evolution of life histories, Oxford: Oxford University Press.

Stewart, R.E., 1994. Size-at-age relationships as discriminators of white whale (Delphinapterus leucas) stocks in the eastern Canadian Arctic. Bioscience, 39, pp.217-225.

Stockwell, C.A., Hendry, A.P. and Kinnison, M.T., 2003. Contemporary evolution meets conservation biology. Trends in Ecology \& Evolution, 18(2), pp.94-101.

Suydam, R.S. 2009. Age, growth, reproduction and movements of beluga whales (Delphinapterus leucas) from the eastern Chukchi Sea. Ph.D. thesis, University of Washington, Seattle, WA. 152 p.

Valladares, F., Matesanz, S., Guilhaumon, F., Araujo, M.B., Balaguer, L., Benito-Garzon, M., Cornwell, W., Gianoli, E., van Kleunen, M., Naya, D.E. and Nicotra, A.B., 2014. The effects of phenotypic plasticity and local adaptation on forecasts of species range shifts under climate change. Ecology letters, 17(11), pp.1351-1364.

Wade, P.R., Reeves, R.R. and Mesnick, S.L., 2012. Social and behavioural factors in cetacean responses to overexploitation: are odontocetes less "resilient" than mysticetes?. Journal of Marine Biology, 2012.

Ward, E.J., Holmes, E.E. and Balcomb, K.C., 2009. Quantifying the effects of prey abundance on killer whale reproduction. Journal of Applied Ecology, 46(3), pp.632-640.

Waugh, D. A., Suydam, R. S., Ortiz, J. D. \& Thewissen, J. G. M. 2018. Validation of growth layer group (GLG) depositional rate using daily incremental growth lines in the dentin of beluga (Delphinapterus leucas (Pallas, 1776)) teeth. PLoS One 13, 1-15.

Watt C. A., M. Marcoux, S. H. Ferguson, M. O. Hammill, and C. J.D. Matthews. 2020. Population dynamics of the threatened Cumberland Sound beluga (Delphinapterus leucas) population. In press Arctic Science.

Zuur, A.F., Ieno, E.N., Walker, N.J., Saveliev, A.A., Smith, G.M. and Walker, N.J., 2009. Statistics for biology and health. Gail M, Krickeberg K, Samet JM, Tsiatis a, Wong W (eds) Mixed effects models and extensions in ecology with R. Springer, New York, NY.

Zuur, A.F., Ieno, E.N. and Elphick, C.S., 2010. A protocol for data exploration to avoid common statistical problems. Methods in ecology and evolution, 1(1), pp.3-14.

Table 1: Modeled relationships explaining variation in female beluga whale ovarian reproductive activity (ORA) measured as total corpora counts relative to region (Baffin Bay: BB $(\mathrm{n}=20)$, Hudson Bay: HB $(\mathrm{n}=80))$, body length $(\mathrm{cm})$, and age $(\mathrm{y})$. Step 1 summarizes model selection and complete model information. Step 2 describes model information for the lowest AIC model from each region (BB and $\mathrm{HB}$ ) separately. Model selection criteria includes degrees of freedom (df), log-likelihood (logLik), AICc values, Delta ([?]AICc), and AICc weights (weight - relative likelihood of the model).

Step 1 complete model:

Model Selection Table:

Model df logLik AICc Delta weight 
ORA age + length $4-565.41136 .90 .000 .402$

ORA region + age + length 5 -564.4 1137.10 .160 .371

ORA age 3 -567.4 1138.81 .890 .071

ORA region + age $4-567.11140 .43 .470 .071$

Comprehensive Model:

Estimate Std. Error z value $P$

(Intercept) $0.3844 \quad 0.2496 \quad 1.5400 .1236$

region 0.096500 .067271 .4340 .1515

age $0.035620 .00187319 .016<0.001 * * *$

length 0.0020540 .00067353 .0500 .00229 **

Step 2 by regions:

Baffin Bay model selection table

Model df $\operatorname{logLik}$ AICc Delta weight

ORA age 2 -94.351 193.00 .000 .73

ORA age + length 3 -94.180 195.0 1.99 0.27

ORA length 2 -160.474 325.3 132.250.00

Comprehensive Model:

Estimate Std. Error z value $P$

(Intercept) $0.1902 \quad 0.49 .40 \quad 0.3850 .70$

age $0.057760 .00501911 .508<2 \mathrm{e}-16$ ***

length 0.0007920 .0013580 .5830 .56

Hudson Bay model selection table

Model df logLik AICc Delta weight

ORA age + length 3 -447.937 902.10.00 0.950

ORA age 2 -451.929 908.0 5.890 .050

ORA length $2-572.1421148 .4246 .310 .000$

Comprehensive Model:

Estimate Std. Error z value $P$

(Intercept) $0.605060 .296452 .0410 .0412^{*}$

Age $0.035490 .002333715 .209<2 \mathrm{e}-16$ ***

Length $0.0018770 .00085312 .2000 .0278 *$

\section{Figures}

Figure 1. Study area delineating the two regions representing core (Baffin Bay - red) and peripheral (Hudson Bay - blue) beluga whale populations and the 16 Nunavut, Canada communities where sampling took place. Darker colours represent summer range that is used to define the populations. 
Figure 2. Comparing frequency of female beluga whale ages (top) and lengths (bottom) between Baffin Bay (red) and Hudson Bay (blue).

Figure 3. Linear relationship between female ovarian reproductive activity (ORA) and body length for Baffin Bay (red; ORA $=0.5029+-0.0496$ (length) $-3.749+-1.326 ; \mathrm{r}^{2}=0.766, \mathrm{p}<0.001$ ) and Hudson Bay (blue; ORA $=0.3311+-0.0367$ (length) $\left.-0.1331+-1.135 ; \mathrm{r}^{2}=0.439, \mathrm{p}<0.001\right)$ beluga whale populations

Figure 1.
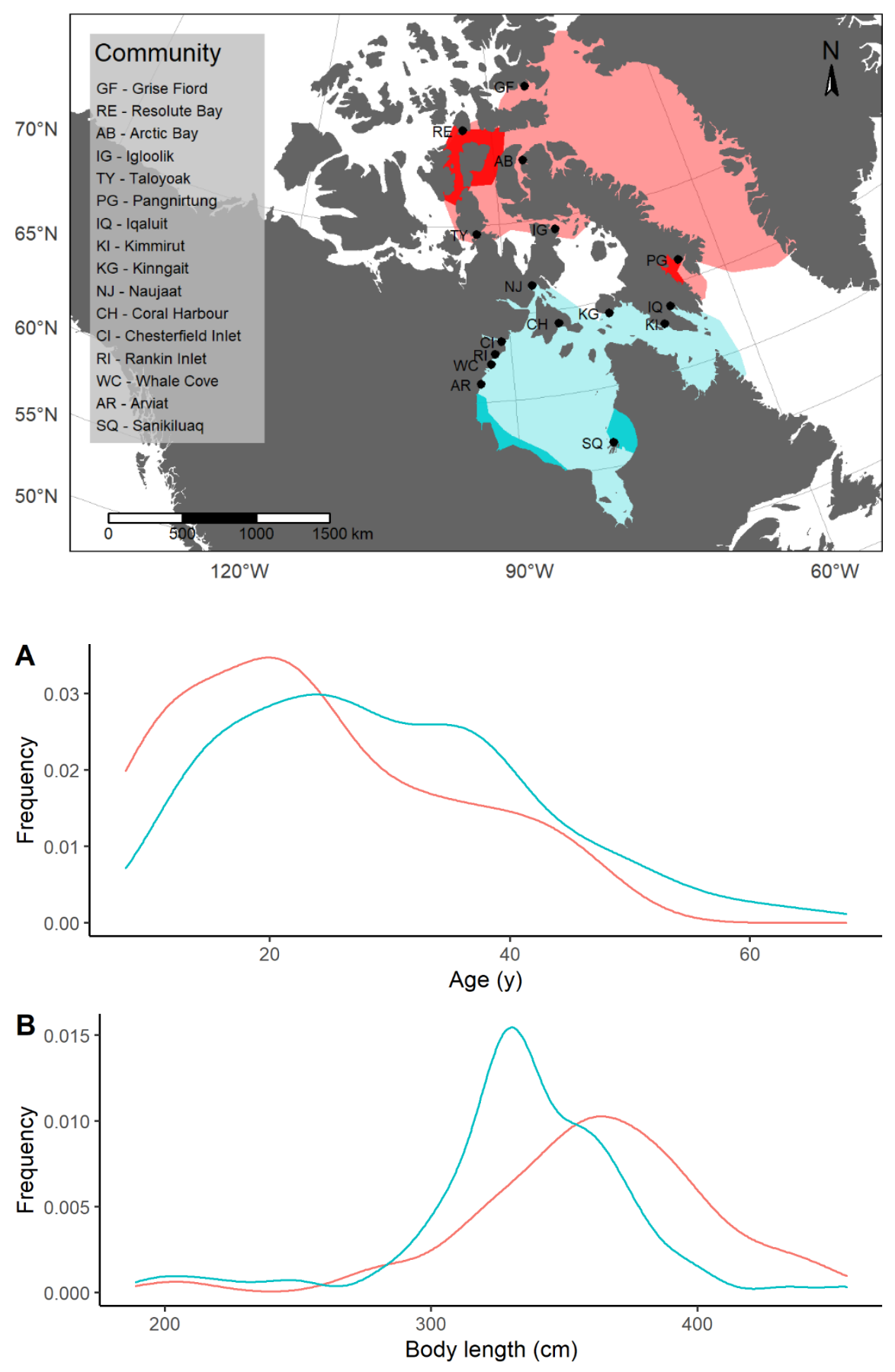
Figure 2 .

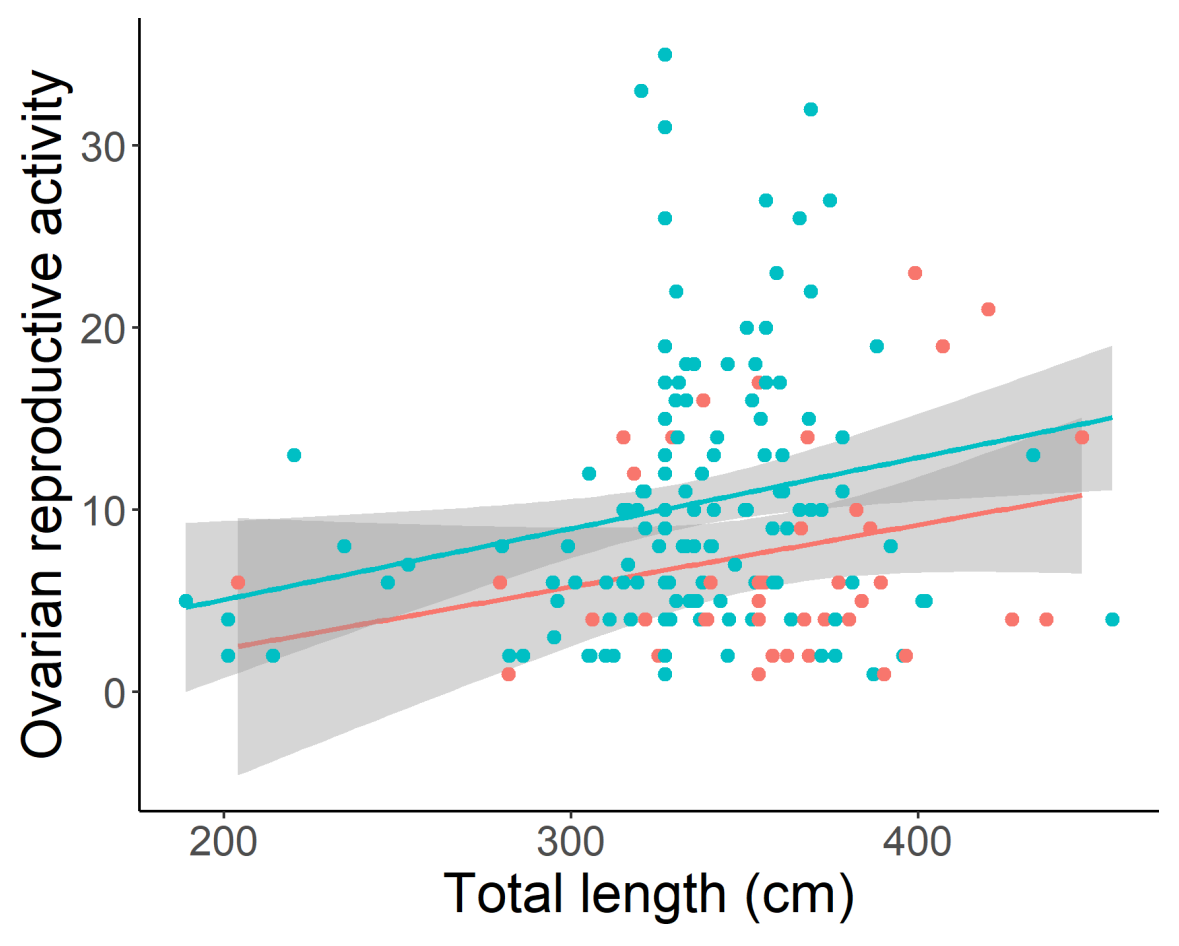

Figure 3. 